\title{
Three-level (NPC) shunt active power filter topology for harmonic reduction using different control
} strategies

\author{
L. Benyettou*, M. Tebbakh \\ Laboratory of Electrical Engineering, University of M'sila, Algeria
}

Corresponding Author Email: benyettou.loutfi_lge@yahoo.fr

https://doi.org/10.18280/mmc_a.910403

Received: 28 January 2018

Accepted: 15 April 2018

\section{Keywords:}

three-level inverter, Shunt active power filter, instantaneous power, harmonic distortion, control hysteresis, PWM control

\begin{abstract}
The problem of harmonic pollution in distribution electrical networks is becoming more and more worrying with the increasing use of nonlinear loads. This work presents a study and hardware realization of three shunt active filter and the different methods used in their command. The command of three active filter based in two axis: the one harmonic current identification and the other is the control of the current how inject by the active filter in the networks, there are several method to identified harmonic current, instantaneous power and modified instantaneous power, Synchronous reference frame and method based for self tuning filter.

In this paper, topologies and control schemes are proposed for three-level three-phase active power filters. The paper presents the principles of operation and design criteria for both the power and control circuits. Finally, a detailed comparison is established with two types of current controllers are considered: hysteresis and PWM for the quality of the energy supplied relative to the imposed standards is validated with computer simulation using MATLAB. The obtained results showed that source current is sinusoidal and in phase with source voltage. The proposed solution has achieved a low total harmonic distortion demonstrating the effectiveness of the presented method.
\end{abstract}

\section{INTRODUCTION}

Active power filter implemented with two levels voltage source inverters have been widely studied and used to eliminate harmonics and compensate reactive power [1-2]. Due to power handling capabilities of power semiconductors these active power filters are limited in medium power applications. Hybrid topologies shunt passive filter and series active filter were proposed to achieve high power filters [3]. Recently, there has been an increasing interest in using multilevel inverters for high power drives and reactive power and harmonics compensation [4-5]. Multilevel pulse width modulation inverters can be used as active power filter for high power applications solving the problem of power semiconductor limitation. The use of neutral-point-clamped (NPC) inverters allows equal voltage shearing of the series connected devices in each phase.

This paper presents an active power filter implemented with a three level NPC voltage source inverter. The proposed current control and DC capacitor voltage control schemes are simple to implement. The hysteresis and PWM technique are employed to generate the inverter switching signals and $p-q$ theory [6-7] for harmonic current identification. MATLAB power system blocks are used to carry out the simulation work.

\section{DESCRIPTION OF THE APF TOPOLOGY}

Figure 1 presents a classical three-leg shunt active power system. It is composed of a grid (esi for $\mathrm{i}=\{1,2,3\}$ ), a nonlinear load, a voltage source converter. The load is a three phase diode rectifier feeding a series $(\mathrm{R}, \mathrm{L})$ load. The grid is supposed to be balanced with equal series resistance $R_{c c}$ and inductance $L_{c c}$ for each phase. The static converter is a voltage source inverter with equal series inductance $L_{f}$ for each phase [8-9].

The output currents of the shunt active filter are controlled by Hysteresis controllers and PWM control to provide reactive power and harmonic currents generated by the non-linear load to ensure filtering. Several faulty cases can occur: power switch or power switch driver can be faulty. In each case, it results in the following models:

- A switch is closed instead of being normally open. It results in a short-circuit of the DC voltage source, increasing is 123 current. To isolate the faulty switch as fast as possible, one can use fuses.

- A switch is open instead of being normally closed. It results in an open phase. The filter may continue injecting currents to the power supply. These currents don't cause any prompt risk because they are at the same range level as the case of no-fault condition. However, the filter in this case is polluting more the power supply instead of elimination of harmonic currents of non-linear load. This case is considered in this paper. 


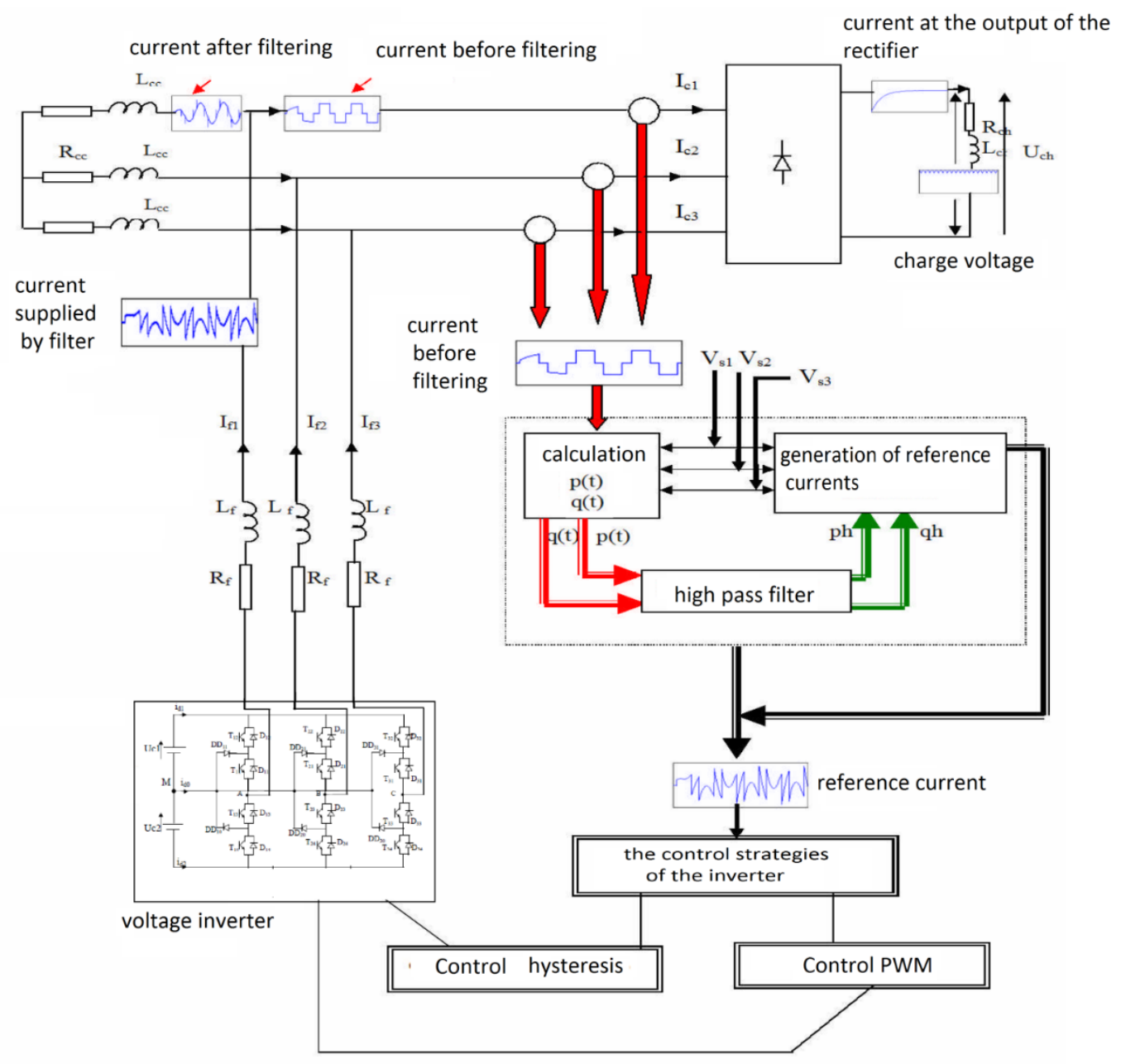

Figure 1. Active power filter operation

\subsection{Three-level voltage inverter}

Figure 2, describes the structure of three-level voltage inverter. The diodes are used to make the connection with the point of reference $\mathrm{O}$ to obtain Midpoint voltages. In order to produce a voltage of $\mathrm{N}$-Levels, $\mathrm{N}-1$ capacities are required. The voltage across each condenser is equal to $\mathrm{E} /(\mathrm{N}-1), \mathrm{E}$ is the total voltage of the DC source. Each couple of switches (S1, S3) form a cell of commutation, the two switches are ordered in a complementary way [10].

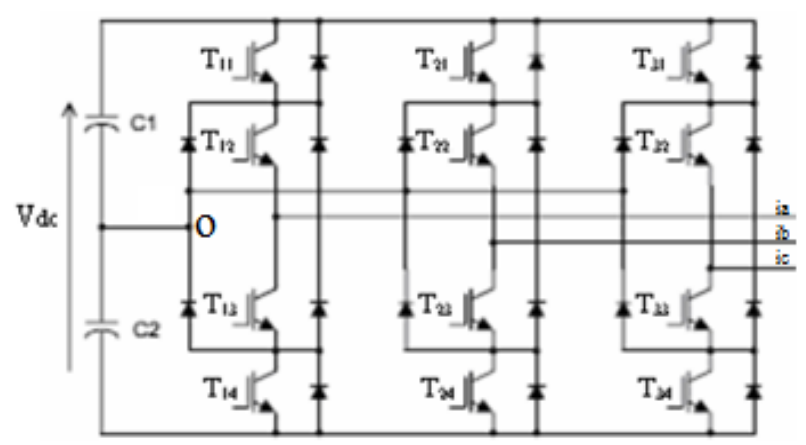

Figure 2. Structure of three-level voltage inverter

The inverter provides three voltage levels according to (1):

$v_{i o}=K_{i} \cdot E / 2$ where

$V_{i o}$ : is the phase-to-middle fictive point voltage

$K_{i}$ : is the switching state variable $\left(\mathrm{K}_{\mathrm{i}}=1,0,-1\right)$

$E$ : is the DC source voltage

$i$ : is the phase index $(\mathrm{i}=\mathrm{a}, \mathrm{b}, \mathrm{c})$. The three-level voltages are shown in Table $1(\mathrm{E} / 2,0,-\mathrm{E} / 2)$

Table 1. Obtaining of three-level inverters

\begin{tabular}{|c|c|c|c|c|c|}
\hline $\boldsymbol{K}_{\boldsymbol{i}}$ & $\boldsymbol{T}_{\boldsymbol{i} \boldsymbol{1}}$ & $\boldsymbol{T}_{\boldsymbol{i} 2}$ & $\boldsymbol{T}_{\boldsymbol{i} 3}$ & $\boldsymbol{T}_{\boldsymbol{i} \boldsymbol{4}}$ & $\boldsymbol{V}_{\boldsymbol{i} \boldsymbol{i}}$ \\
\hline 1 & 1 & 1 & 0 & 0 & $\mathrm{E} / 2$ \\
\hline 0 & 0 & 1 & 1 & 0 & 0 \\
\hline-1 & 0 & 0 & 1 & 1 & $-\mathrm{E} / 2$ \\
\hline
\end{tabular}

The phase-to-neutral point voltage $V_{\text {in }}$ is linked to $V_{\text {io }}$ via:

$v_{i n}=v_{i o}+v_{n o}$

Assuming that the system is balanced, then:

$v_{a n}+v_{b n}+v_{c n}=0$

By substituting (3) in (2), the equation presented below is obtained:

$v_{n o}=1 / 3\left(v_{a o}+v_{b o}+v_{c o}\right)$ 
The expressions of instantaneous inverter phase output voltages are obtained by replacing (4) in (2):

$$
\left[\begin{array}{l}
v_{a n} \\
v_{b n} \\
v_{c n}
\end{array}\right]=\left[\begin{array}{c}
2 / 3-1 / 3-1 / 3 \\
-1 / 32 / 3-1 / 3 \\
-1 / 3-1 / 32 / 3
\end{array}\right] \cdot\left[\begin{array}{l}
v_{a o} \\
v_{b o} \\
v_{c o}
\end{array}\right]
$$

The line to line voltages are determined by the following equation:

$$
\left[\begin{array}{l}
v_{a b} \\
v_{b c} \\
v_{c a}
\end{array}\right]=\left[\begin{array}{ccc}
1 & -1 & 1 \\
0 & 1 & -1 \\
-1 & 0 & 0
\end{array}\right] \cdot\left[\begin{array}{l}
v_{a o} \\
v_{b o} \\
v_{c o}
\end{array}\right]
$$

\subsection{Reference current calculation}

Several methods were proposed for the identification of the harmonic current references. Mainly, the methods based on the FFT (Fast Fourier Transformation) in the frequency domain and the methods based on instantaneous power calculation in the time domain. In this study, the $p q$ theory method is used allowing the compensation of harmonic currents, reactive power and unbalanced currents. The reference currents (harmonic currents) identification is based on $\alpha-\beta$ transformation to obtain real and imaginary powers. The voltages $\left(\mathrm{V}_{\mathrm{S} 1}, \mathrm{~V}_{\mathrm{S} 2}, \mathrm{~V}_{\mathrm{S} 3}\right)$ and currents $\left(\mathrm{I}_{\mathrm{S} 1}, \mathrm{I}_{\mathrm{S} 2}, \mathrm{I}_{\mathrm{S} 3}\right)$ are transformed to bi-phase system according to the following equation [8]:

$$
\left[\begin{array}{l}
X_{s \alpha} \\
X_{s \beta}
\end{array}\right]=\sqrt{\frac{2}{3}}\left[\begin{array}{ccc}
1 & -\frac{1}{2} & -\frac{1}{2} \\
0 & \frac{\sqrt{3}}{2} & -\frac{\sqrt{3}}{2}
\end{array}\right] \cdot\left[\begin{array}{l}
X_{1} \\
X_{2} \\
X_{3}
\end{array}\right]
$$

The instantaneous active and reactive powers of the system are calculated as follows:

$\left[\begin{array}{c}p \\ q\end{array}\right]=\left[\begin{array}{cc}v_{s \alpha} & v_{s \beta} \\ -v_{s \beta} & v_{s \alpha}\end{array}\right] \cdot\left[\begin{array}{c}i_{c \alpha} \\ i_{c \beta}\end{array}\right]$

Instantaneous powers are composed from a constant part and a variable part corresponding to fundamental and harmonic currents respectively.

$$
\left[\begin{array}{c}
i_{c \alpha} \\
i_{c \beta}
\end{array}\right]=\frac{1}{v_{s \alpha}^{2}+v_{s \beta}^{2}}\left[\begin{array}{cc}
v_{s \alpha} & -v_{s \beta} \\
v_{s \beta} & v_{s \alpha}
\end{array}\right] \cdot\left[\begin{array}{l}
\tilde{p} \\
\tilde{q}
\end{array}\right]
$$

\section{CURRENT CONTROL BY HYSTERESIS}

The method is based on the comparison of the difference $\varepsilon$ between the current reference and the measured currents with a fixed band. Each violation of this band gives a switching command switches to Figure 3.

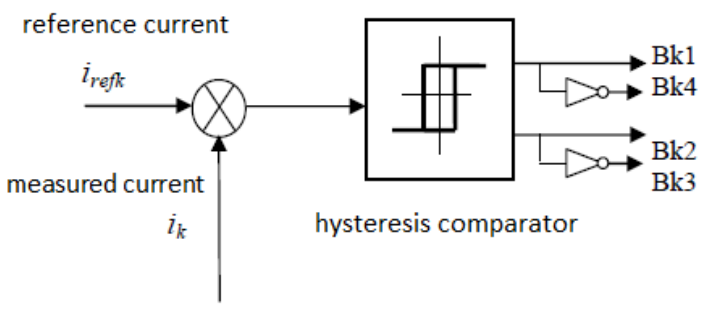

Figure 3. Principle of current control by hysteresis

Hysteresis control algorithm for the three-level inverter. The Bks control commands of the switches of the arm $\mathrm{k}$ are given by the following algorithm:

$$
\left\{\begin{array}{l}
\operatorname{Si}\left|\left(\varepsilon_{k} \geq h\right) \&\left(\varepsilon_{k \leq 2 h}\right)\right| \text { ou } \mid\left(\varepsilon_{k} \leq-h\right) \&\left(\varepsilon_{k \geq-2 h)} \mid \Rightarrow B_{k 1}=0 \& B_{k 2}=1\right. \\
\operatorname{Si}\left(\varepsilon_{k<2 h}\right) \Rightarrow B_{k 1}=0 \& B_{k 2}=0 \\
\operatorname{Si}\left(\varepsilon_{k}>2 h\right) \Rightarrow B_{k 1}=1 \& B_{k 2}=1
\end{array}\right.
$$

\section{HARMONIC CURRENTS CONTROL USING PWM}

This control implements initially a proportional controller which starts from the difference between the injected current (active filter current) and reference current (identified current) that determines the reference voltage of the inverter (modulating wave). This standard reference voltage is compared with two carrying triangular identical waves shifted one from other by a half period of chopping. The control of inverter arm constituting the filter is summarized in the two following stages.

- Determination of the intermediate signals $\mathrm{V}_{\mathrm{i} 1}$ and $\mathrm{V}_{\mathrm{i} 2}$.

If error $\geq$ carrying $1=>V_{\mathrm{i} 1}=1$

If error $<$ carrying $1=>V_{i 1}=0$

If error $\geq$ carrying $2=>V_{\mathrm{i} 2}=0$

If error $<$ carrying $2=>V_{i 2}=-1$

- Determination of control signals of the switches $T_{i j}(j=1,2$, $3,4)$.

If $\left(\mathrm{V}_{\mathrm{i} 1}+\mathrm{V}_{\mathrm{i} 2}\right)=1=>\mathrm{T}_{\mathrm{i} 1}=1, \mathrm{~T}_{\mathrm{i} 2}=1, \mathrm{~T}_{\mathrm{i} 3}=0, \mathrm{~T}_{\mathrm{i} 4}=0$

If $\left(\mathrm{V}_{\mathrm{i} 1}+\mathrm{V}_{\mathrm{i} 2}\right)=0=>\mathrm{T}_{\mathrm{i} 1}=0, \mathrm{~T}_{\mathrm{i} 2}=1, \mathrm{~T}_{\mathrm{i} 3}=1, \mathrm{~T}_{\mathrm{i} 4}=0$

If $\left(\mathrm{V}_{\mathrm{i} 1}+\mathrm{V}_{\mathrm{i} 2}\right)=-1 \Rightarrow \mathrm{T}_{\mathrm{i} 1}=0, \mathrm{~T}_{\mathrm{i} 2}=0, \mathrm{~T}_{\mathrm{i} 3}=1, \mathrm{~T}_{\mathrm{i} 4}=1$

The general block diagram of control currents is illustrated in Figure 4.

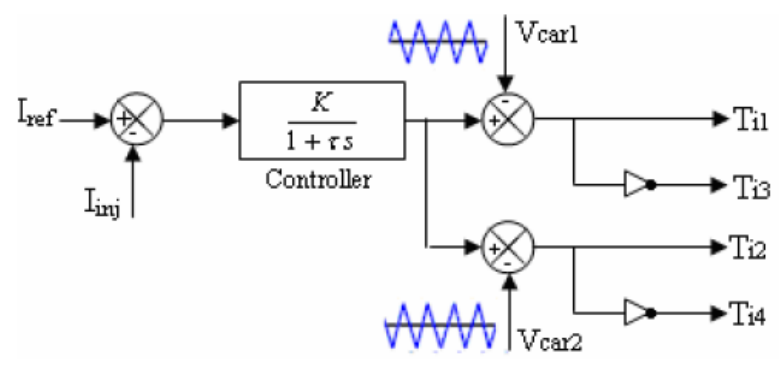

Figure 4. PWM synoptic block diagram of currents control

\section{DC CAPACITOR VOLTAGE CONTROL}

The capacitors $(C 1$ and $C 2)$ average voltage $(V d c 1, V d c 2)$ 
has to be maintained at a fixed value. The main cause of its variation is the active filter switching losses and output filter. To ensure inverter permanent and continuous voltage supply, a controlled scheme is adopted as illustrated in Figure 5.

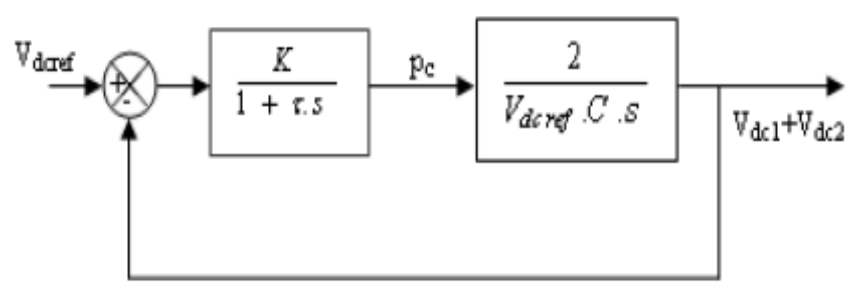

Figure 5. Dc voltage control block

\section{RESULTS OF THE SIMULATION}

The simulation is carried out using a program working in MATLAB Simulink environment. The simulation parameters
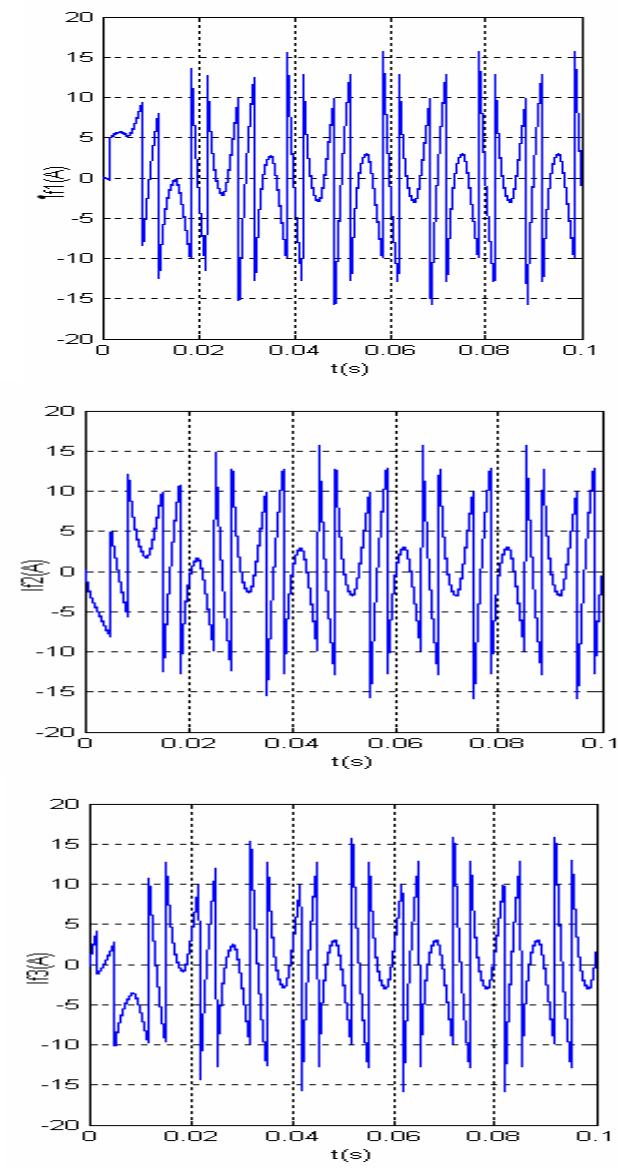

are shown in Table 2, presented below.

Table 2. Simulation parameters

\begin{tabular}{|l|l|}
\hline \multirow{2}{*}{ Source settings } & $\mathrm{Rcc}=311.10-6 \Omega$ \\
\cline { 2 - 2 } Active filter settings & $\mathrm{Lcc}=0.2136 .10-6 \mathrm{H}$ \\
\cline { 2 - 2 } & $\mathrm{Rf}=0.2 \Omega$ \\
\hline \multirow{2}{*}{ Load parameters } & $\mathrm{Rch}=13.004 \mathrm{H}$ \\
\cline { 2 - 2 } & $\mathrm{Lch}=0.1 \mathrm{H}$ \\
\hline \multirow{3}{*}{$\begin{array}{l}\text { For the load variation at } \\
\mathrm{t}=0.04 \mathrm{~s}\end{array}$} & $\begin{array}{l}\text { From } 0 \mathrm{~s} \text { to } 0.04 \mathrm{~s}: \mathrm{Rch}=30.13 \Omega, \mathrm{Lch} \\
=0.014 \mathrm{H}\end{array}$ \\
\cline { 2 - 2 } & $\begin{array}{l}\text { From } 0.04 \mathrm{~s} \text { to } 0.1 \mathrm{~s}: \mathrm{Rch}=13.13 \Omega, \\
\mathrm{Lch}=0.1 \mathrm{H}\end{array}$ \\
\hline
\end{tabular}

The frequency spectrum of the line currents presents the presence of several harmonics of amplitudes which coincide with those developed theoretically (THDI $=31.63 \%$ ).

\subsection{Hysteresis control strategy for a band $\Delta h=0.1 \mathrm{~A}$}
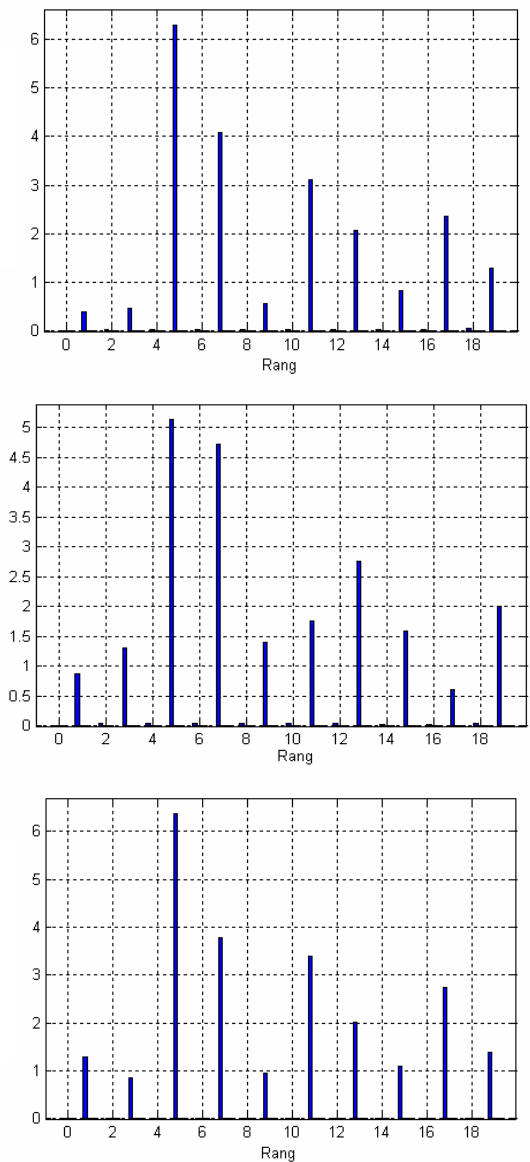

Figure 7. Currents injected by the inverter and their frequency spectra for the hysteresis control $(\Delta \mathrm{h}=0.1 \mathrm{~A})$
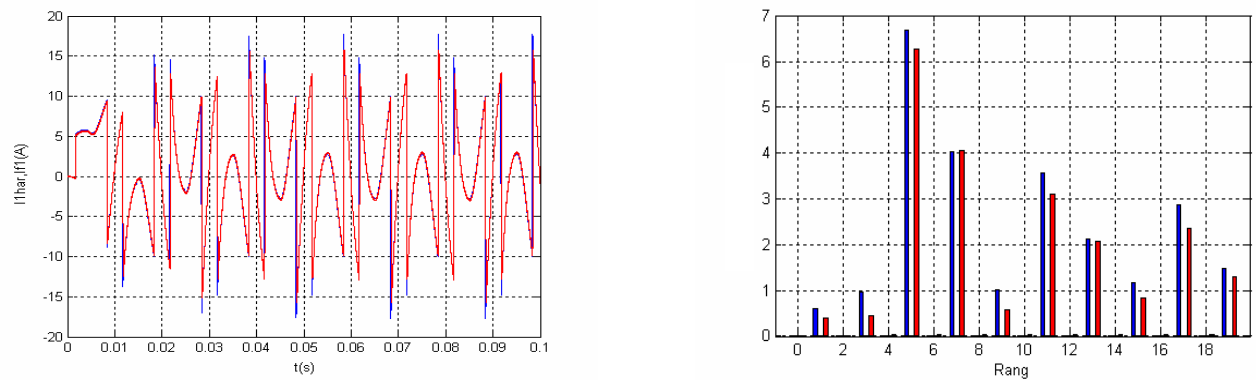

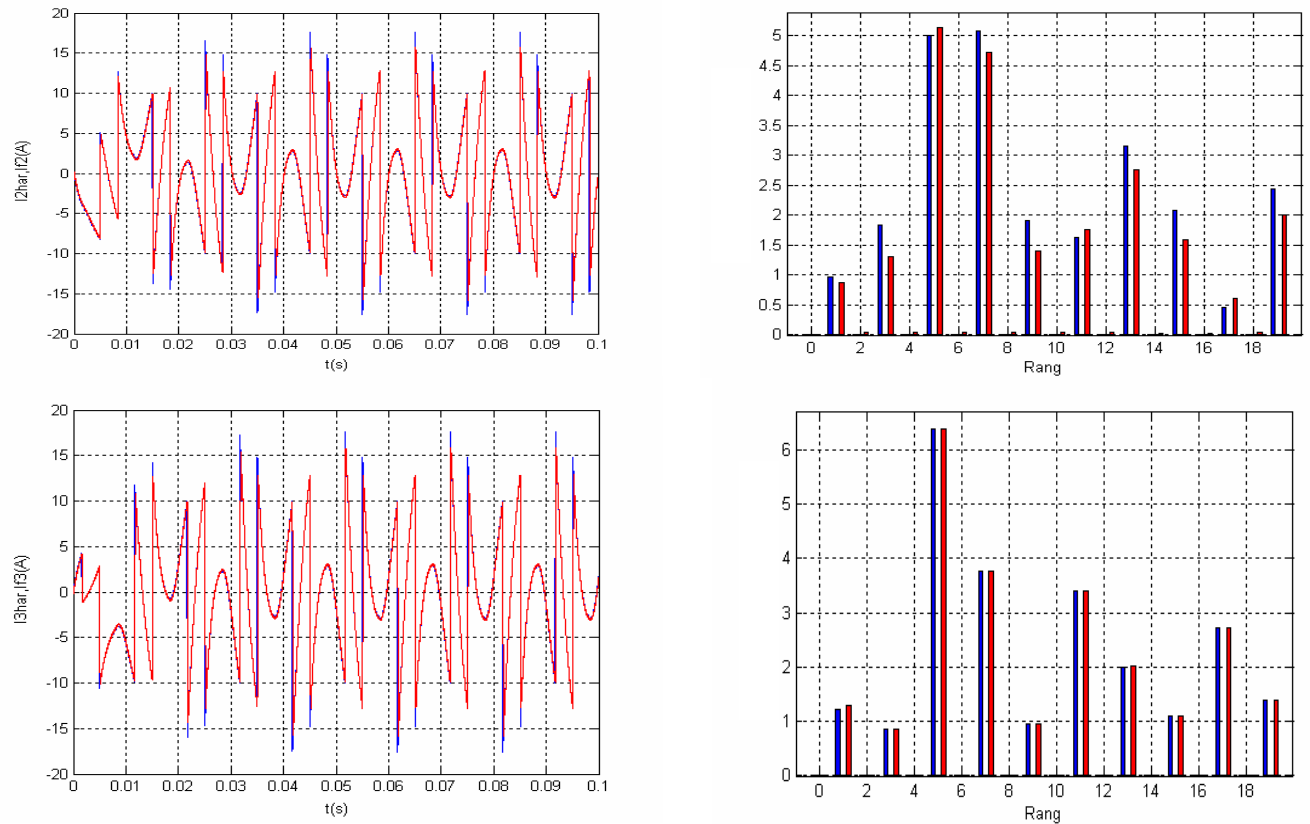

Figure 8. Reference currents, injected and their frequency spectra for the hysteresis control $(\Delta \mathrm{h}=0.1 \mathrm{~A})$
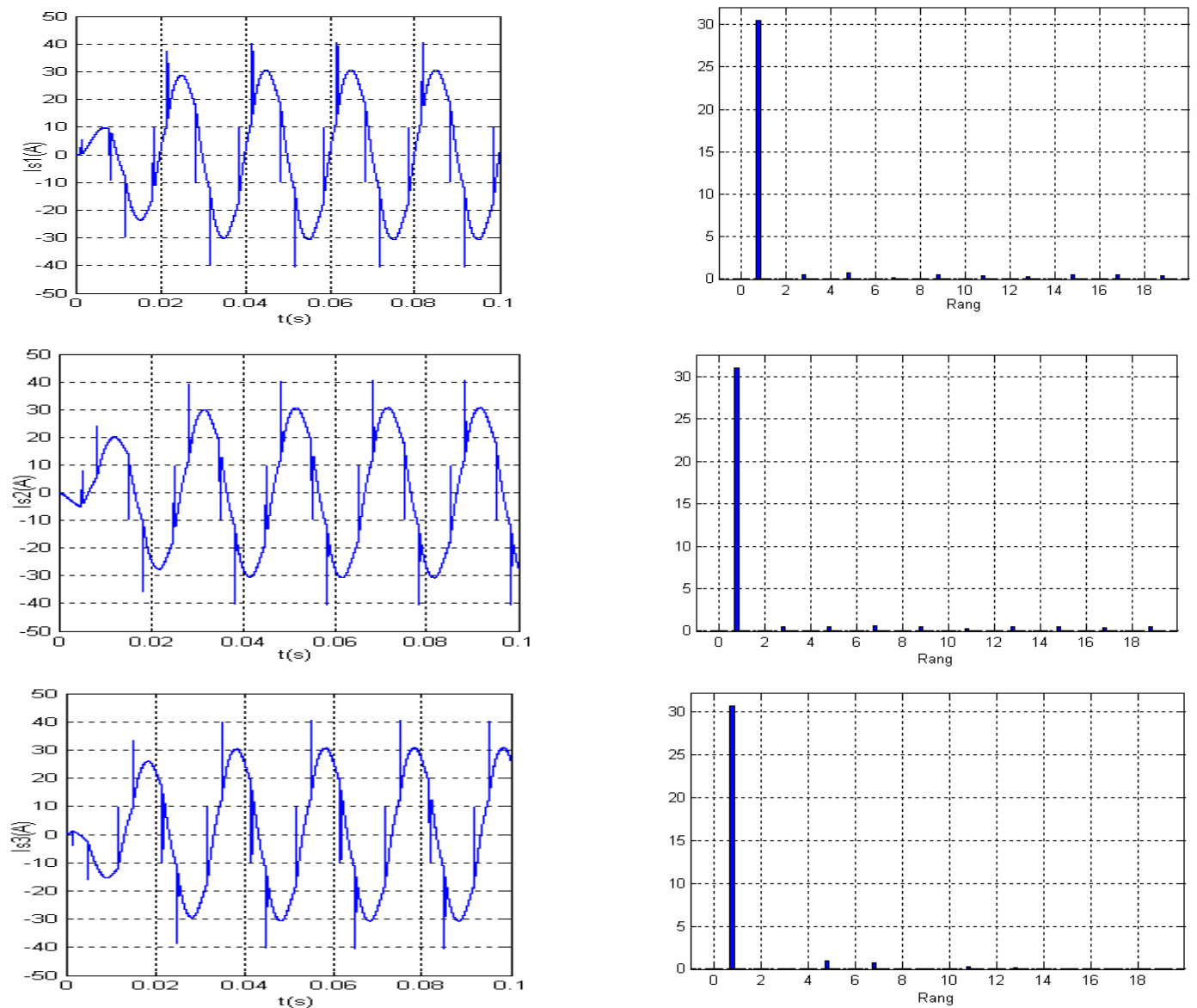

Figure 9. Source currents after filtering and their frequency spectra for the hysteresis control $(\Delta \mathrm{h}=0.1 \mathrm{~A})$ 

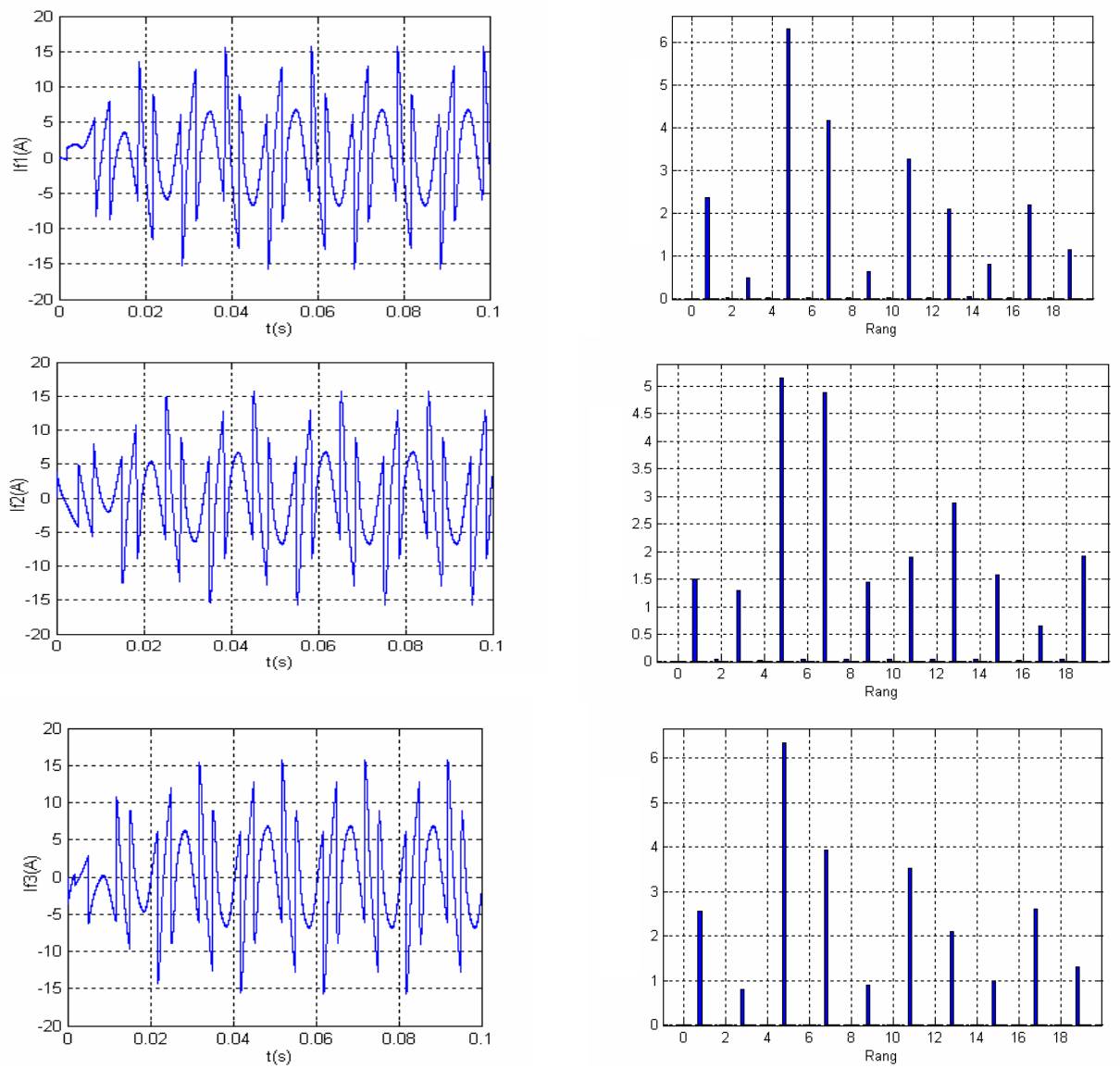

Figure 10. Currents injected by the inverter and their frequency spectra for the hysteresis control $(\Delta \mathrm{h}=1 \mathrm{~A})$
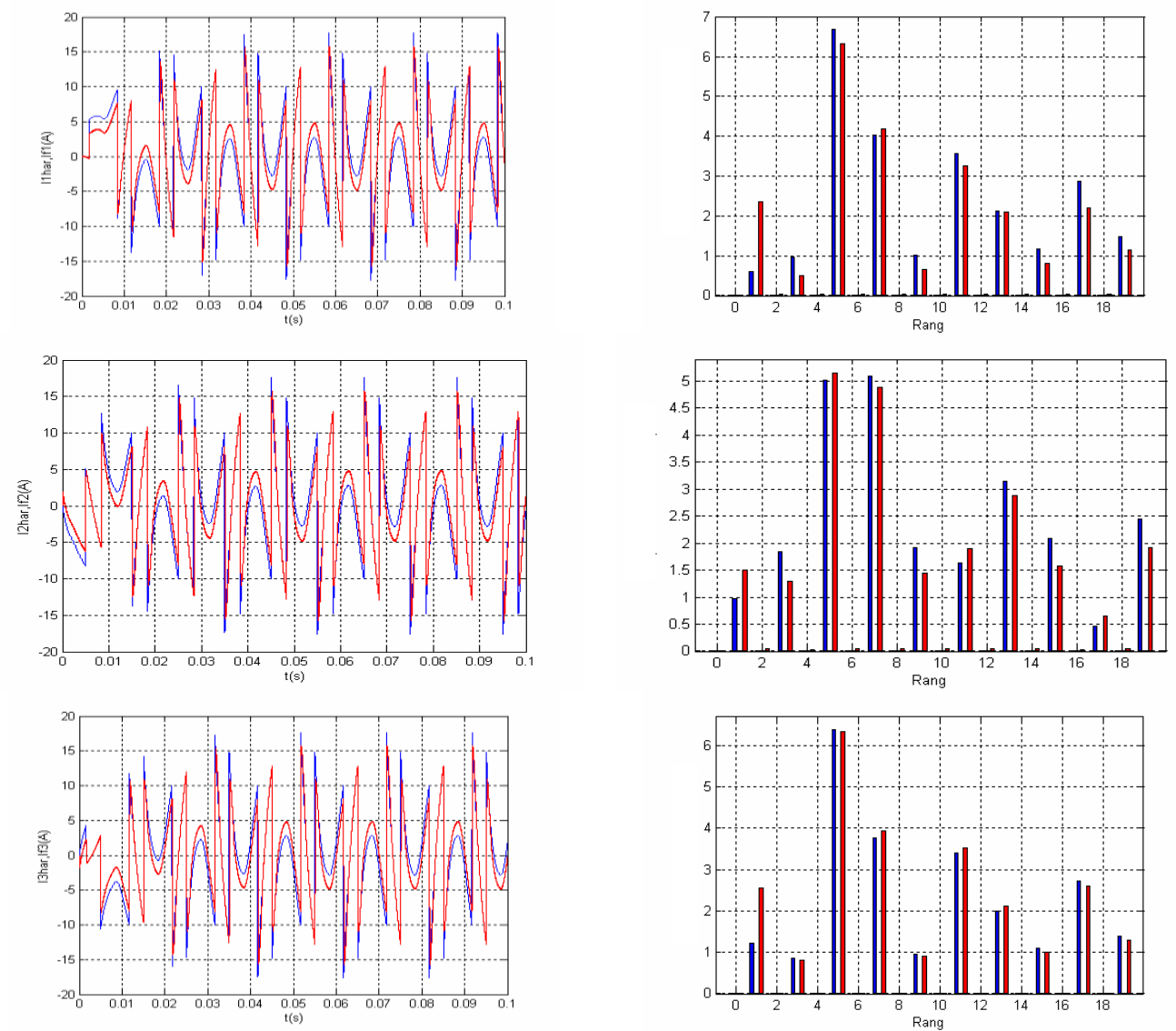

Figure 11. Reference currents, injected and their spectra for control with hysteresis $(\Delta h=1 \mathrm{~A})$ 

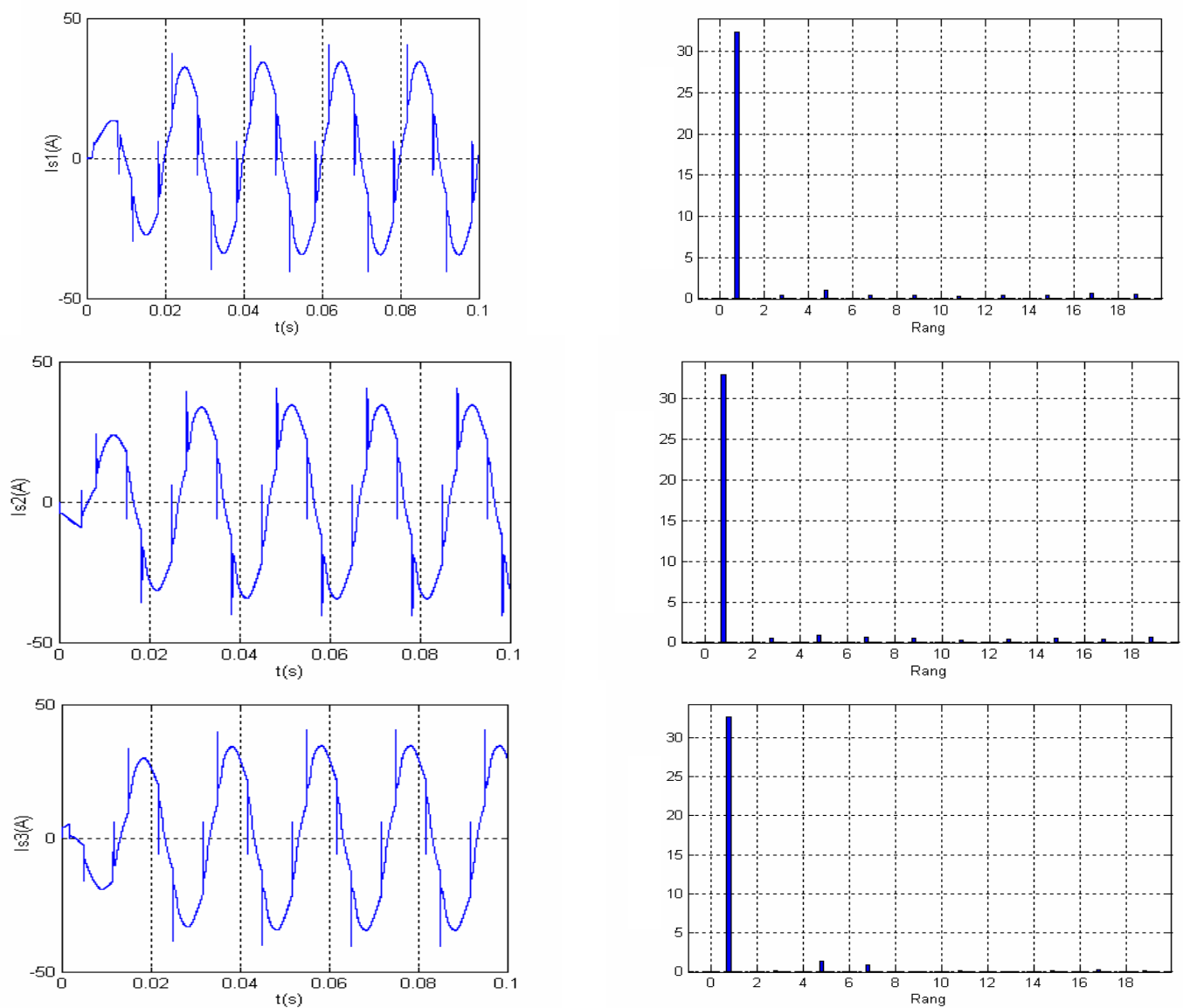

Figure 12. Source currents after filtering and their frequency spectra for the hysteresis control $(\Delta \mathrm{h}=1 \mathrm{~A})$

\subsection{MLI command with two carriers for a frequency $2500 \mathrm{~Hz}$}
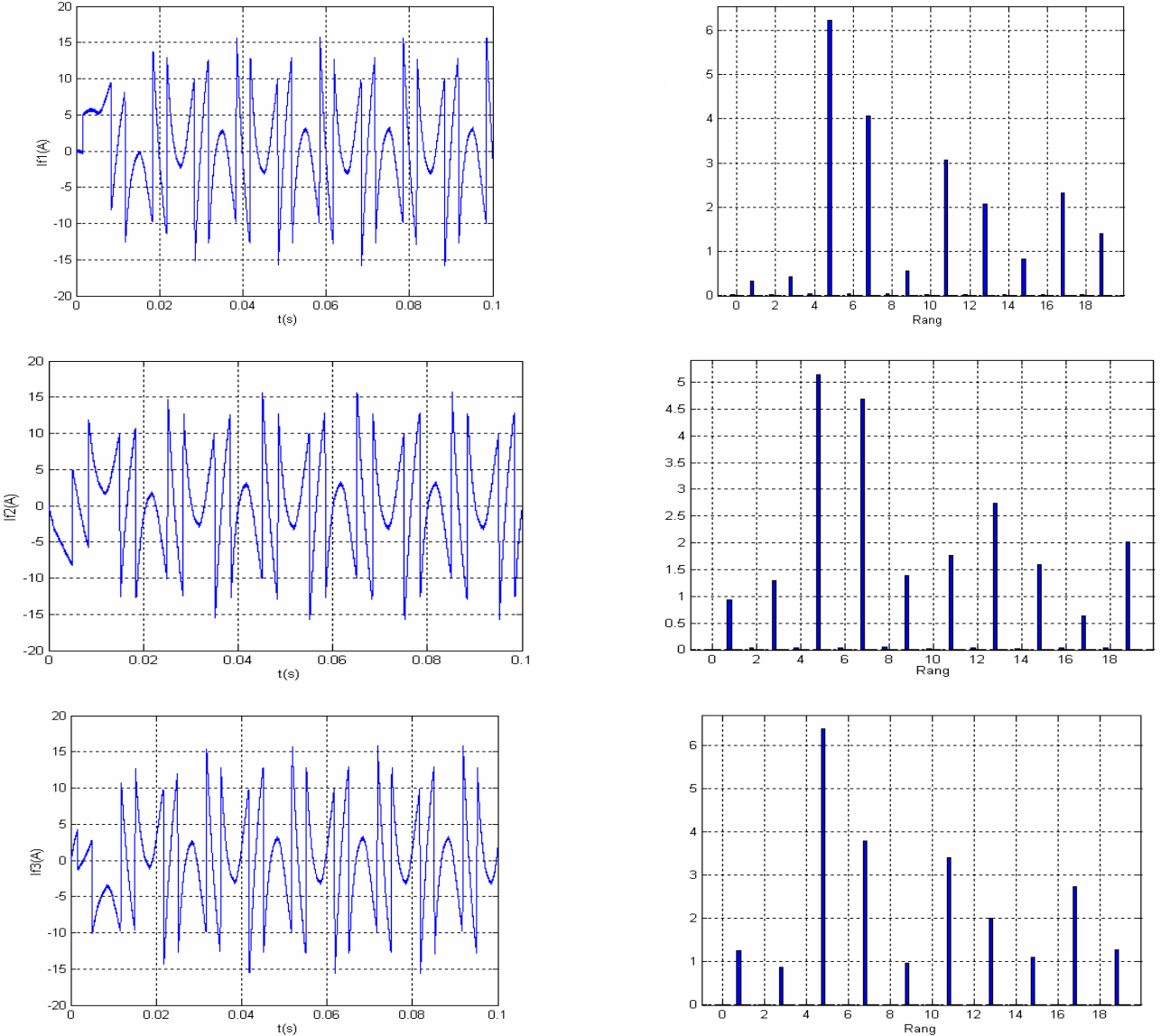

Figure 13. Currents injected by the filter and their frequency spectra for the control at MLI (fp=2500 Hz) 

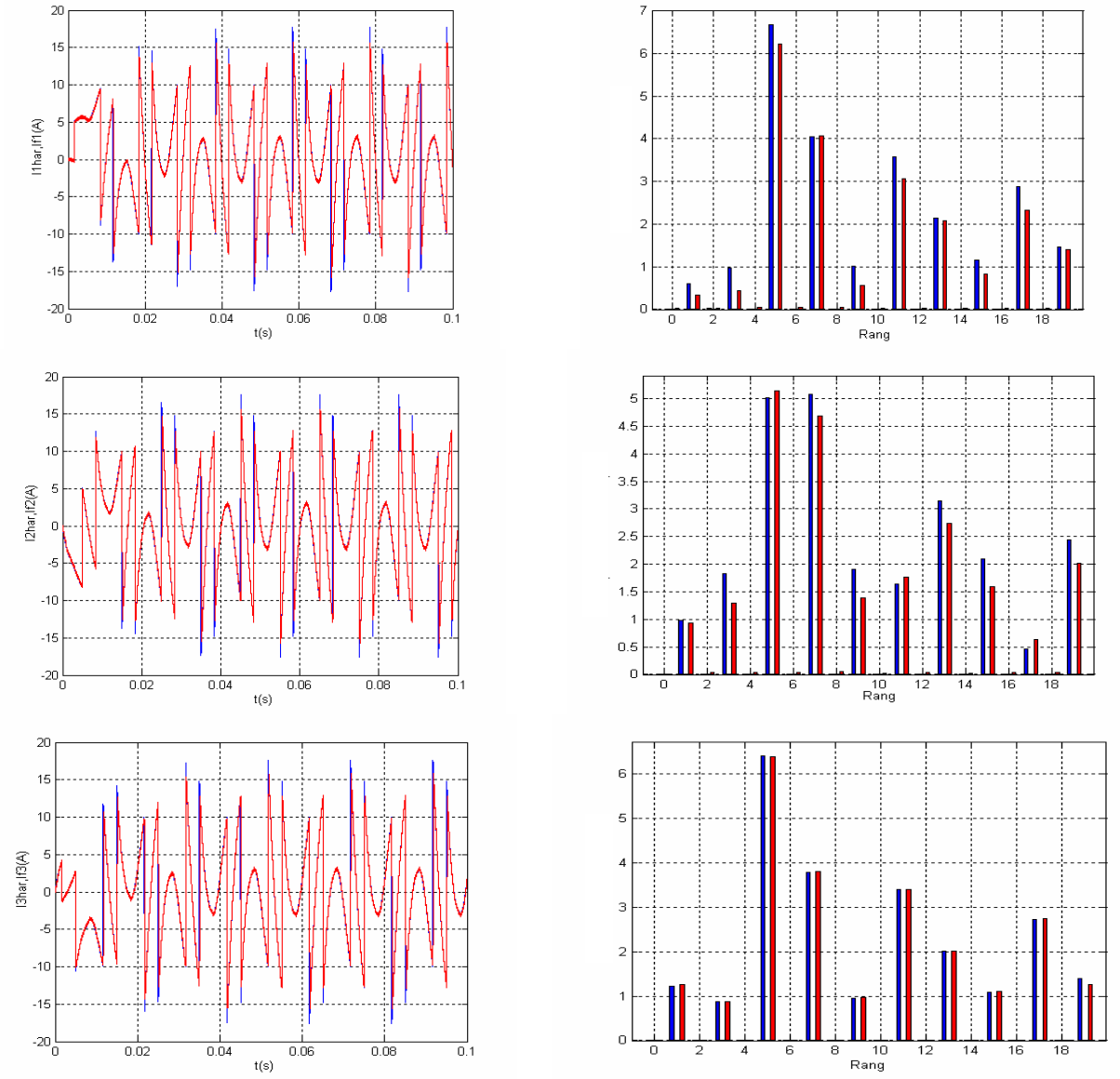

Figure 14. Reference currents, injected and their frequency spectra for the PWM control $(\mathrm{fp}=2500 \mathrm{~Hz})$
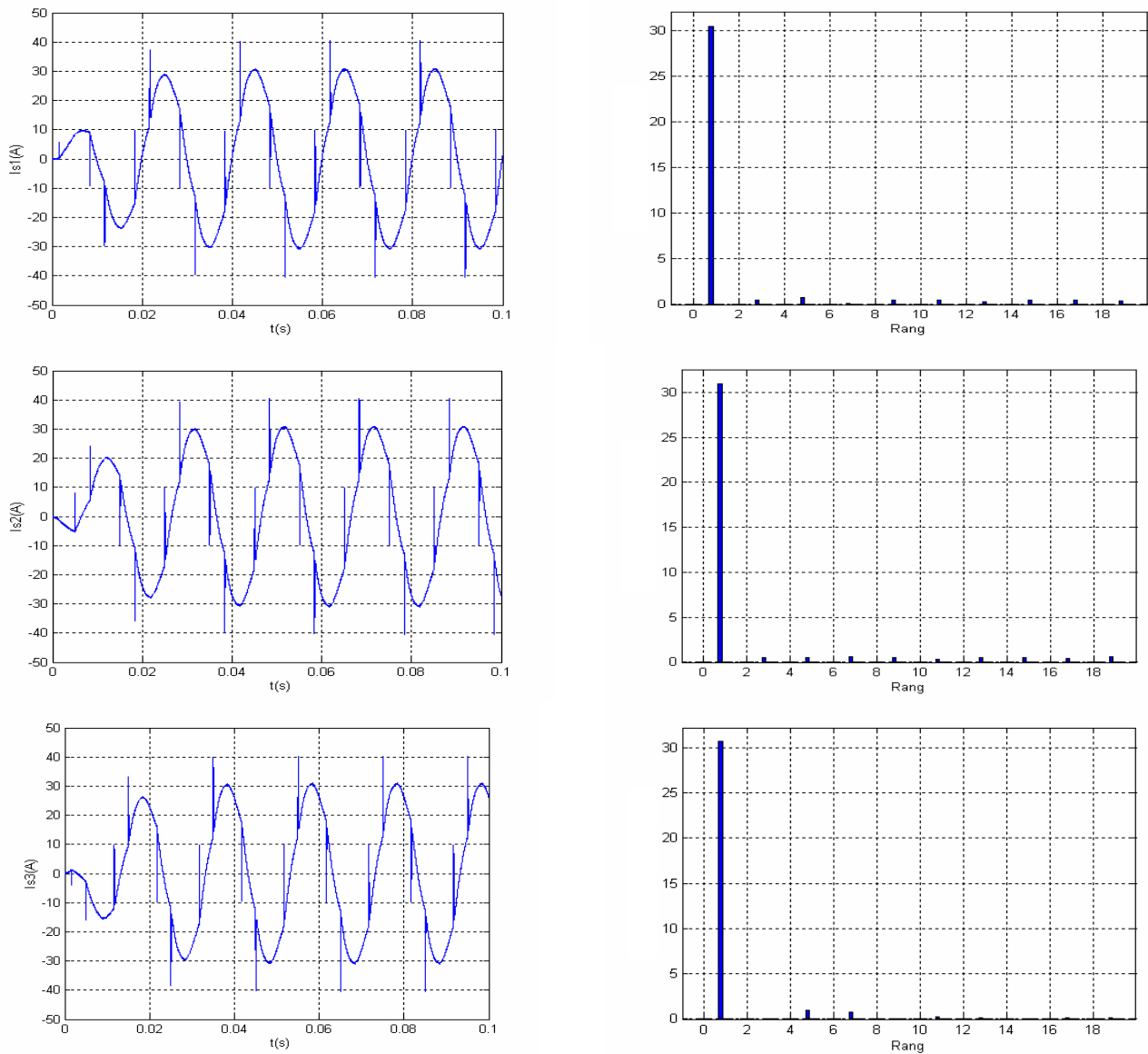

Figure 15. Source currents after filtering and their frequency spectra for the PWM control ( $\mathrm{fp}=2500 \mathrm{~Hz}$ ) 

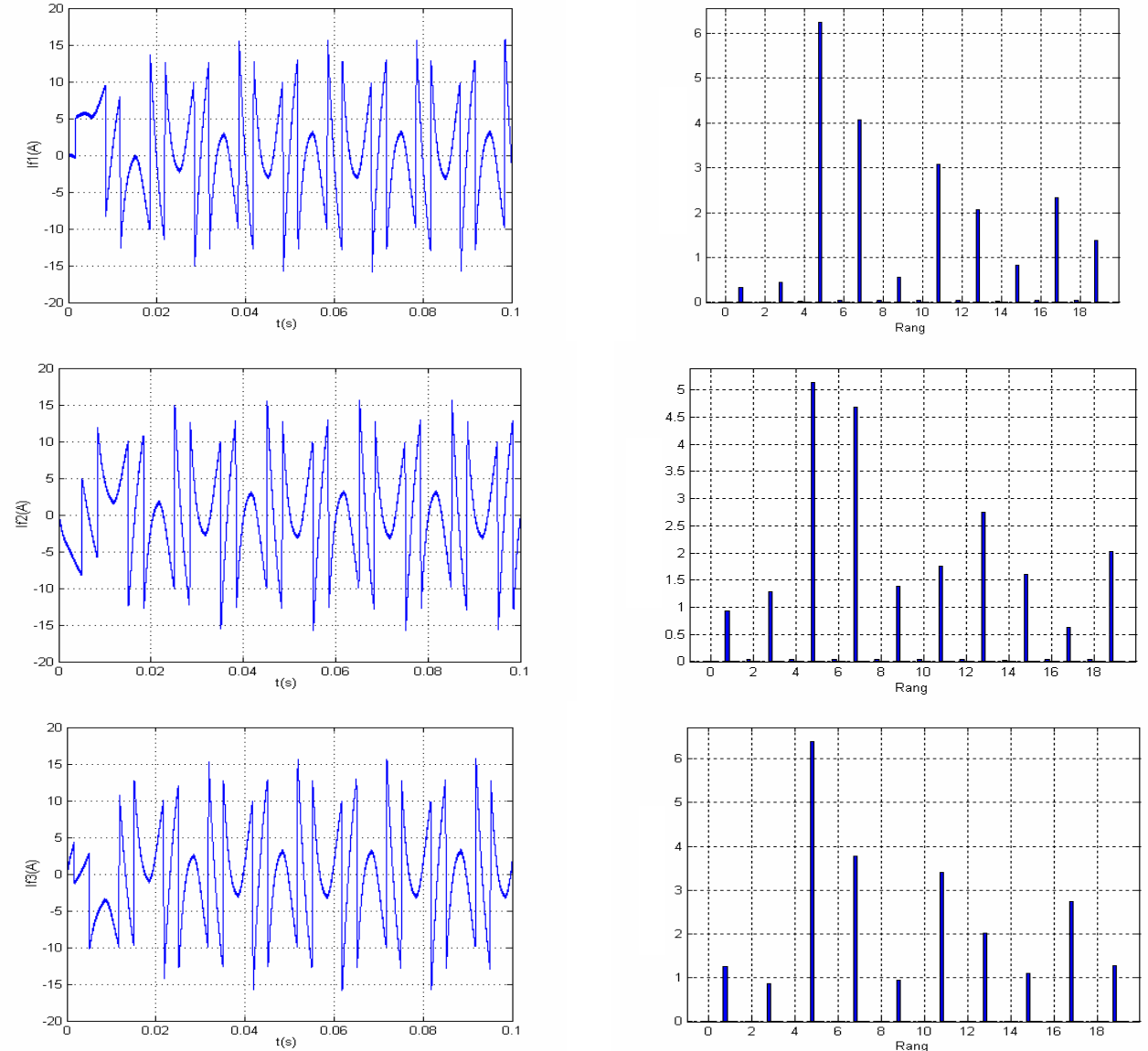

Figure 16. Currents injected by the filter and their frequency spectra for the control at MLI (fp=7500 Hz)
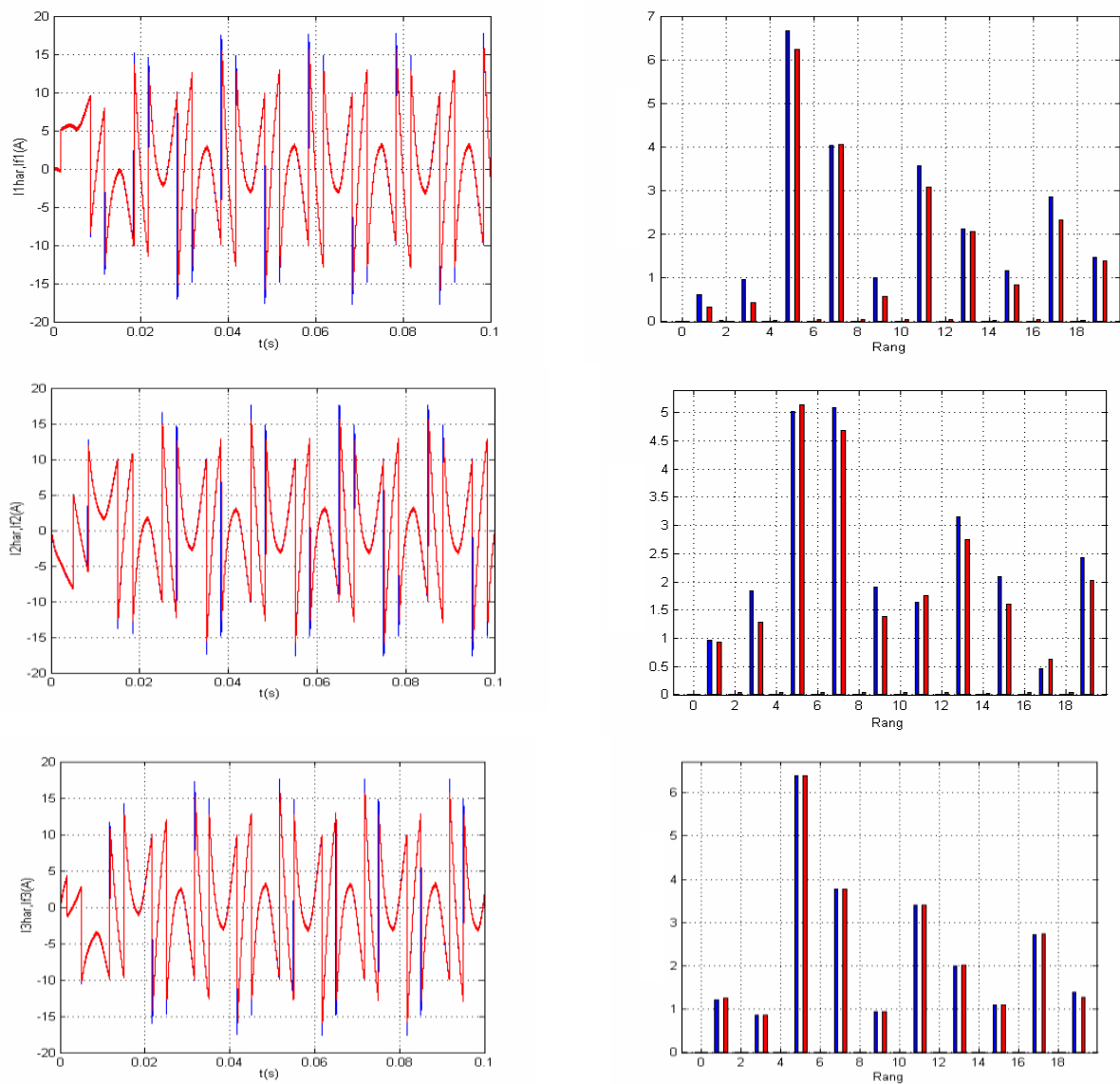

Figure 17. Reference currents, injected and their frequency spectra for the PWM control (fp=7500 $\mathrm{Hz})$ 

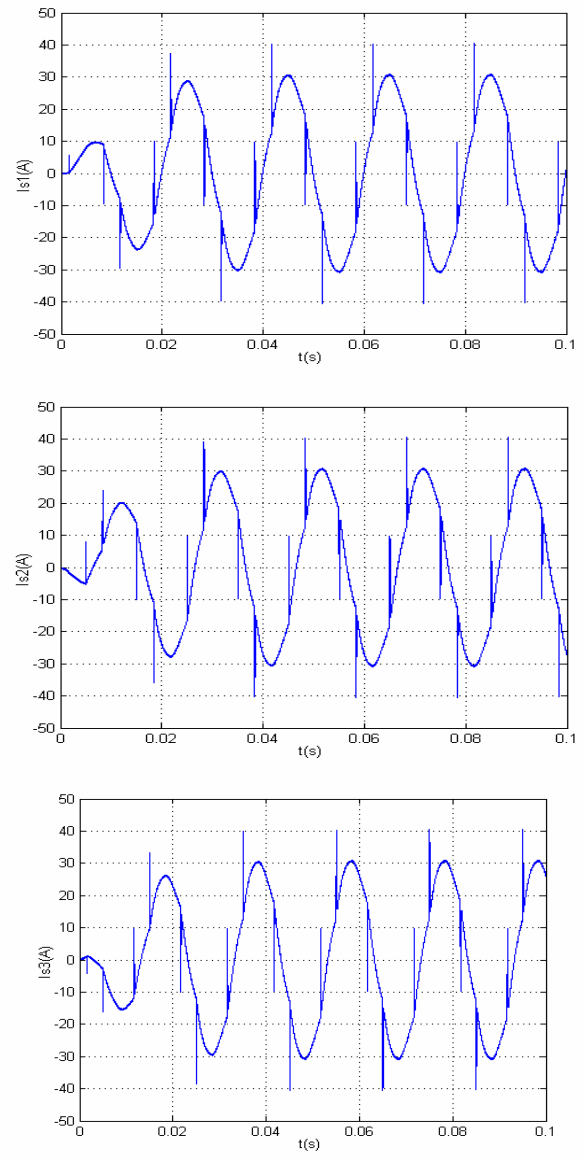
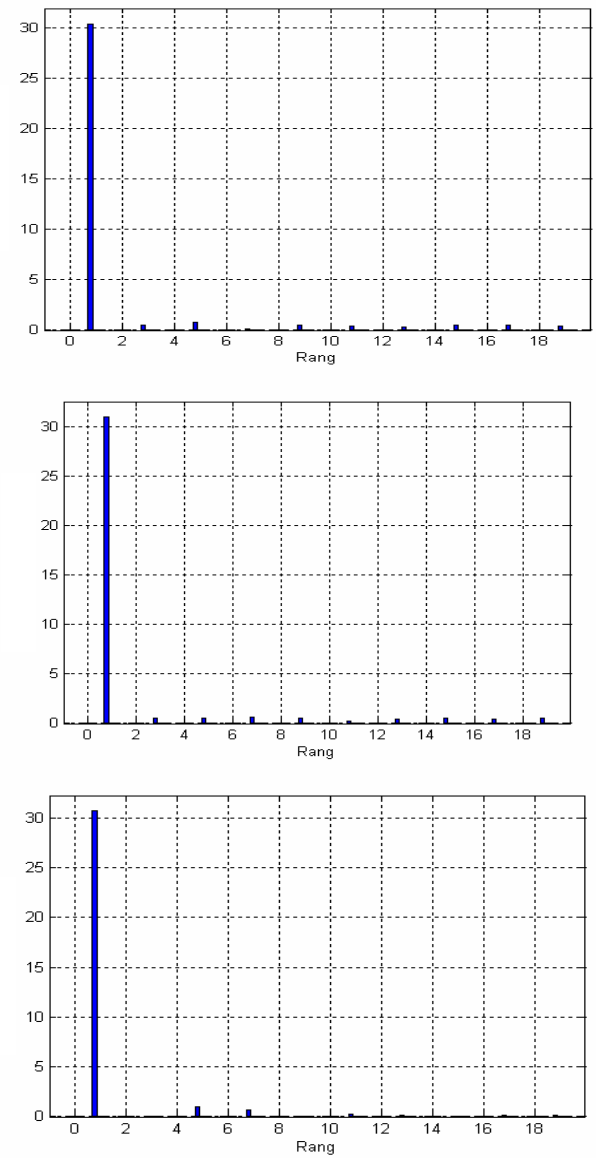

Figure 18. Source currents after filtering and their frequency spectra for the PWM control (fp=7500 Hz)

\section{RESULTS AND DISCUSSIONS}

The table below present the summary results of the different simulations obtained for the direct control strategy applied to the topologies of Three-level shunt active power filter.

Table 3. Synthesis of the results

\begin{tabular}{|l|c|c|}
\hline & & THD $\%$ \\
\hline \multirow{2}{*}{ Controlled hysteresis } & $\Delta \mathrm{h}=0.1 \mathrm{~A}$ & $4.17 \%$ \\
\cline { 2 - 3 } & $\Delta \mathrm{h}=1 \mathrm{~A}$ & $4.96 \%$ \\
\hline \multirow{2}{*}{ Controlled PWM } & $\mathrm{fp}=2500 \mathrm{~Hz}$ & $4.21 \%$ \\
\cline { 2 - 3 } & $\mathrm{fp}=7500 \mathrm{~Hz}$ & $4.18 \%$ \\
\hline
\end{tabular}

Three-level shunt active power filter performances are related to current references quality, $\mathrm{p}-\mathrm{q}$ theory is used for harmonic currents identification and calculation the obtained current is shown in Figure 8. This method is very important; it allows harmonic currents and reactive power compensation simultaneously, the obtained current and voltage waveforms are in phase as illustrated the Figure 9, 12, 15 and 18.

-The reduction of the hysteresis band leads to an improvement of the quality of the

currents: $(\mathrm{THD}=4.17 \%$ for $\Delta \mathrm{h}=0.1 \mathrm{~A}$ and $\mathrm{THD}=4.96 \%$ for the case $\Delta \mathrm{h}=1 \mathrm{~A})$.

- The increase of the hash frequency leads to an improvement of the quality of the currents: (THD $=4.21 \%$ for $\mathrm{fp}=2500 \mathrm{~Hz}$ and $\mathrm{THD}=4.18 \%$ for $\mathrm{fp}=7500 \mathrm{~Hz}$ ).

\section{CONCLUSION}

A theoretical study with simulation of three-level shunt active power filter controlled with the hysteresis and PWM modulation was presented and analyzed in this paper. The three-level APF provides numerous advantages such as improvement of the supply current wave form, less harmonic distortion (THD $<5 \%$ ), which responds well to international standards and its use in high power/medium voltage with a lower maximum device rating. The effectiveness of the proposed scheme is proved by simulation using MATLAB.

\section{REFERENCES}

[1] Akagi H. (1995). Utility applications of power electronics. Proceedings of International Power Electronics Conference, Yokohama 95: 19-22.

[2] Akagi H. (1994). Trend in active power line conditioners. IEEE Trans. On Ind. Electronics 9(3): 263-268. http://dx.doi.org/10.1109/63.311258

[3] Al-Zamel AM, Torrey DA. (1999). A three phase hybrid series passive/shunt active filter system. IEEE Transactions on Power Electronics 875-881. http://dx.doi.org/10.1109/APEC.1999.750471

[4] Akagi H, Nabae A, Atoh S. (1986). Control strategy of active power filters using multiple voltage source PWM converters. IEEE Transactions on Industry Applications 22(3): 460-465. 
[5] Lin BR, Chiang HK, Huang CH. (2006). Three-phase three-level active power filter with a clamped capacitor topology. IEE Proceedings - Electric Power Applications 153(4): $\quad 513-522 . \quad$ https://doi.org/10.1049/ipepa:20050363

[6] Akagi H, Kanazawa Y, Nabae A. (1983). Generalized theory of the instantaneous reactive power in three-phase circuits. In Proceedings of the 1985 International Power Electronics Conference, Tokyo, Japan, pp. 1375-1386.

[7] Gaiceau M. (2005). Active power compensator of the current harmonics based on the instantaneous power theory. The annals of "dunarea de jos" University of Galati FASCLE III. ISSN 1221-454X: 23-28.

[8] Benyettou L, Benslimane T, Bentata K, Abdelkhalek O.
(2015). Open transistor faults characterization novel method for cascaded h-bridge five-level three-phase shunt active power filter. Modelling, Measurement and Control A 88(1): 53-70.

[9] Abaali H, Lamchich MT, RaoufiDecoupled M. (2014). State-feedback controller of three phase shunt active power filter: Unbalanced current compensation. Modelling, Measurement and Control A 87(3): 57-67.

[10] Salim C., Toufik BM. (2014). Three-level (NPC) shunt active power filter performances based on fuzzy controller for harmonic currents compensation under non-ideal voltage conditions. International Journal on Electrical Engineering and Informatics 6(2): 342-358. 